\title{
Brucellosis at the animal/ecosystem/human interface at the beginning of the 21st century
}

\author{
J. Godfroid ${ }^{\mathrm{a}, \mathrm{b}, *}$, H.C. Scholz ${ }^{\mathrm{c}}$, T. Barbier ${ }^{\mathrm{d}}$, C. Nicolas ${ }^{\mathrm{d}}$, P. Wattiau ${ }^{\mathrm{e}}$, D. Fretin ${ }^{\mathrm{e}}$, \\ A.M. Whatmore ${ }^{\text {f }}$, A. Cloeckaert ${ }^{g}$, J.M. Blasco ${ }^{\text {h }}$, I. Moriyon ${ }^{\mathrm{i}}$, C. Saegerman ${ }^{\mathrm{j}}$, \\ J.B. Muma ${ }^{\mathrm{k}}$, S. Al Dahouk ${ }^{1, \mathrm{~m}}$, H. Neubauer ${ }^{\mathrm{n}}$, J.-J. Letesson ${ }^{\mathrm{d}}$ \\ a Department of Food Safety and Infection Biology, Norwegian School of Veterinary Science, Tromsø, Norway \\ b Department of Veterinary Tropical Diseases, Faculty of Veterinary Science, University of Pretoria, Onderstepoort, South Africa \\ c Bundeswehr, Institute of Microbiology, Department of Bacteriology, Munich, Germany \\ d Research Unit in Molecular Biology, University of Namur, Namur, Belgium \\ e Veterinary and Agrochemical Research Centre, Brussels, Belgium \\ ${ }^{\mathrm{f}}$ Veterinary Laboratories Agency, Addlestone, United Kingdom \\ g INRA, UR1282, Infectiologie Animale et Santé Publique, Nouzilly, France \\ h CITA, Unidad de Sanidad Animal, Zaragoza, Spain \\ i Departamento de Microbiología, Universidad de Navarra, Pamplona, Spain \\ j Research Unit of Epidemiology and Risk Analysis Applied to Veterinary Sciences, Faculty of Veterinary Medicine, University of Liège, Liège, Belgium \\ ${ }^{\mathrm{k}}$ Department of Disease Control, School of Veterinary Medicine, University of Zambia, Lusaka, Zambia \\ ${ }^{1}$ Federal Institute for Risk Assessment, Berlin, Germany \\ m RWTH Aachen University, Department of Internal Medicine III, Aachen, Germany \\ ${ }^{n}$ Loeffler Institute, Institute of Bacterial Infections and Zoonoses, Jena, Germany
}

\section{A R T I C L E I N F O}

\section{Keywords:}

Brucella

Brucellosis

Taxonomy

Immunity

Virulence

Metabolism

Vaccine

Epidemiology

Zoonosis

Bioterrorism

"One Health"

\begin{abstract}
A B S T R A C T
Following the recent discovery of new Brucella strains from different animal species and from the environment, ten Brucella species are nowadays included in the genus Brucella. Although the intracellular trafficking of Brucella is well described, the strategies developed by Brucella to survive and multiply in phagocytic and non-phagocytic cells, particularly to access nutriments during its intracellular journey, are still largely unknown. Metabolism and virulence of Brucella are now considered to be two sides of the same coin. Mechanisms presiding to the colonization of the pregnant uterus in different animal species are not known. Vaccination is the cornerstone of control programs in livestock and although the S19, RB51 (both in cattle) and Rev 1 (in sheep and goats) vaccines have been successfully used worldwide, they have drawbacks and thus the ideal brucellosis vaccine is still very much awaited. There is no vaccine available for pigs and wildlife. Animal brucellosis control strategies differ in the developed and the developing world. Most emphasis is put on eradication and on risk analysis to avoid the re-introduction of Brucella in the developed world. Information related to the prevalence of brucellosis is still scarce in the developing world and control programs are rarely implemented. Since there is no vaccine available for humans, prevention of human brucellosis relies on its control in the animal reservoir. Brucella is also considered to be an agent to be used in bio- and agroterrorism attacks. At the animal/ecosystem/human interface it is critical to reduce opportunities for Brucella to jump host species as already seen in livestock, wildlife and humans. This task is a challenge for the future in terms of veterinary public health, as for wildlife and ecosystem managers and will need a "One Health" approach to be successful.
\end{abstract}

(c) 2011 Elsevier B.V. All rights reserved.

\footnotetext{
* Corresponding author at: Norwegian School of Veterinary Science, Department of Food Safety and Infection Biology, Section of Arctic Biology,
} Stakkevollveien 23, 9010 Tromsø, Norway. Tel.: +47 776654 21; fax: +47 77694911.

E-mail address: Jacques.godfroid@nvh.no (J. Godfroid). 


\section{Introduction}

Brucellosis is an economically important disease in production animals worldwide (Corbel, 1997). Brucella melitensis, Brucella abortus and Brucella suis cause abortion and infertility in their natural hosts, goats and sheep, cattle and swine, respectively. Albeit their respective host preferences, Brucella spp. have also been isolated from a great variety of wildlife species. As a consequence, different wildlife species may act merely as spill-over hosts (victims) or as reservoir hosts (vectors) of Brucella spp. for other animal species and humans. Indeed, brucellosis is a zoonosis and humans can acquire a debilitating febrile illness known as 'Mediterranean or undulant fever', as the result of contact with infected animals or consumption of their products (Pappas et al., 2006b). The source of naturally acquired brucellosis in humans is almost always to be found in the animal reservoirs, although very few cases of human to human transmission have been reported (Godfroid et al., 2005).

The ability of Brucella spp. to successfully survive and replicate within different host cells explains their pathogenicity. Extensive replication of Brucella spp. in placental trophoblasts is associated with abortion in their animal preferential hosts, and persistence in macrophages leads to chronic infections that are a hallmark of brucellosis in both natural animal hosts and humans (Roop et al., 2009).

\section{Taxonomy and taxonomical controversies}

The genus Brucella belongs to the family Brucellaceae within the order Rhizobiales of the class Alphaproteobacteria. The closest phylogenetic neighbour of the genus Brucella is the genus Ochrobactrum, a saprophyte that occasionally infects humans. Until 1985, the genus Brucella consisted of 6 species, B. melitensis, B. abortus, B. suis, Brucella ovis, Brucella neotomae and B. ovis, known as the six classical species. All these Brucella species are genetically highly related. In 1985 , it was proposed combining the six species into a single species, $B$. melitensis, with the other species to be recognised as biovars (e.g., $B$. melitensis biovar Abortus 1) (Verger et al., 1985). In 2003, however, the Subcommittee on the Taxonomy of Brucella unanimously agreed on a return to the pre-1986 taxonomic treatment of the genus Brucella, implying re-approval of the six classical Brucella nomenspecies with their corresponding biovars (Osterman and Moriyon, 2006). Since 2007, Brucella ceti and Brucella pinnipedialis (infecting preferentially cetaceans and pinnipeds, respectively) are recognized as new Brucella species (Foster et al., 2007). In 2008, another new Brucella species, i.e., Brucella microti was first isolated in the common vole (Microtus arvalis) (Scholz et al., 2008b) and lastly, Brucella inopinata was recently isolated from a breast implant infection in an elderly woman with clinical signs of brucellosis (Scholz et al., 2010). This species is the only one that has not been isolated from any animal reservoir. To date the genus Brucella consists thus of 10 species. Prospective Brucella species have also been isolated from three native rat species in Australia, but not yet been included in the genus (Tiller et al., 2010) as well as in association with two cases of stillbirth in non-human primates (Schlabritz-Loutsevitch et al., 2009). The preferential hosts and the pathogenicity for humans of the 10 recognized Brucella species are depicted in Table 1.

\section{Brucella life style-surviving immune system of the host}

Within mammalian hosts, Brucella spp. have an intracellular lifestyle and infect both professional and non-professional phagocytes. The VirB operon, a type IV secretion pathway that is induced on phagosomal acidification, plays a key role in intracellular parasitism and is essential for pathogenicity (Boschiroli et al., 2002; O'Callaghan et al., 1999; Ugalde, 1999). Brucella spp. will resist different environmental stresses in these phagocytic cells, modify their intracellular trafficking and eventually reach their replicative niche (Kohler et al., 2002). Brucella spp. survive and multiplie in dendritic cells, interfere with their maturation, impair the antigen processing and thus compromises host immune responses (Roop et al., 2009). Brucella spp. prevent apoptosis within the macrophage and their long-term survival in the reticuloendothelial system of spleen, liver, and bone marrow will sustain chronic infection (Gorvel and Moreno, 2002). During gestation, Brucella spp. replicate in large numbers in placental trophoblasts. The integrity of the placenta may be disrupted and abortion induced. The pregnant uterus is an immunological privileged site, which prevents the rejection of the fetus by modulating local immune responses which in turn may allow Brucella spp. to replicate extensively (Neta et al., 2010). The Brucella lipopolysaccharide (LPS) is a weak inducer of the host inflammatory cytokines IL-1 $\beta$, IL- 6 or TNF- $\alpha$. (Roop et al., 2009) compared to LPS molecules from many other Gram-negative bacterial pathogens. Although Brucella LPS stimulates TLR4, it has lower immunostimulatory activity compared to other Gram-negative bacteria such as Salmonella enterica serotype Typhimurium (Rittig et al., 2003). IFN- $\gamma$ is a key cytokine controlling Brucella infection. One of its major functions is the stimulation of Brucella-killing effector mechanisms in phagocytic cells (Baldwin and Parent, 2002).

The global picture emerging from what is known about Brucella virulence is an extremely efficient adaptation to shield itself from the immune recognition and to manipulate key aspects of host cell physiology (apoptosis, vacuolar trafficking) (Gorvel, 2008; Gorvel and Moreno, 2002; Letesson et al., 2002). It also becomes more and more evident, though still poorly studied, that one of the in vivo adaptation keystones is the ability to finely tune the metabolism according to the various nutrients encountered during the infectious cycle (Brown et al., 2008; Lamontagne et al., 2010). Quorum sensing (QS) is also known to be involved in the regulation of Brucella virulence determinants mostly linked to the cell surface (type IV secretion system, flagellum, Omps and exopolysaccharide) (Letesson et al., 2002; Weeks et al., 2010). When intracellular, in the vacuole, sensing 'Quorum' for Brucella could mean sensing limited diffusion due to space limitation. That corresponds to 'starvation sensing'. It can be suggested that QS is directly or indirectly involved in adjusting the 
Table 1

Brucella species, preferred host and pathogenicity for humans.

\begin{tabular}{|c|c|c|c|}
\hline Brucella species & Biovars & Preferential host(s) & Pathogenicity for humans \\
\hline B. melitensis & $1-3$ & Sheep, goat & High \\
\hline B. abortus & $1-6,9$ & Cattle & High \\
\hline \multirow[t]{4}{*}{ B. suis } & 1,3 & Pig & High \\
\hline & 2 & Wild boar, hare & $\mathrm{No}^{\mathrm{a}}$ \\
\hline & 4 & Reindeer, caribou & High \\
\hline & 5 & Rodents & No \\
\hline B. neotomae & - & Desert wood rat & No \\
\hline B. ovis & - & Ram & No \\
\hline B. canis & - & Dog & Moderate \\
\hline B. ceti & - & Cetaceans & Unknown ${ }^{\mathrm{b}}$ \\
\hline B. pinnipedialis & - & Pinnipeds & Unknown ${ }^{b}$ \\
\hline B. microti & - & Soil, vole, fox & Unknown \\
\hline B. inopinata & - & Unkown & High \\
\hline
\end{tabular}

a One case of $B$. suis biovar 2 infection in an immuno-compromised hunter has been described in France.

b One human laboratory contamination has been described in the UK. Two naturally acquired cases have been described, although the source of infection could not be traced back to marine mammals.

metabolism of Brucella. Indeed, by slowing down the basic metabolism of Brucella, QS would prevent multiplication until the replicative compartment is reached. A similar proposal was made for the BvrR/BvrS two component system (TCS) (Lamontagne et al., 2010; Viadas et al., 2010). Both the BvrR/BvrS TCS and the QS system could contribute to the adaptation of the metabolic network during the nutrient shift faced by Brucella all along its intracellular trafficking. Also the phosphoenolpyruvate phosphotransferase system (PTS) of $B$. melitensis senses the metabolic state of the cell leading to a coordinated regulation of $C$ and $N$ metabolisms and as well as some key virulence genes, e.g., the virB operon (Dozot et al., 2010), flagellar genes (Fretin et al., 2005).

\section{Molecular detection and identification}

Classically, detection and identification of Brucella spp. has been based on cultural and phenotypic analysis (biotyping). Although undoubtedly providing valuable information, biotyping was, and remains, a highly specialised and time-consuming approach requiring experienced staff and well-optimised non-commercial reagents ideally used under secured biological containment. Initial PCR methods were based on the 16S rRNA and bcsp31 genes (Baily et al., 1992; Herman and Deridder, 1992). PCR methods based on the 16S rRNA amplify a DNA fragment common to all Brucella species but cross-react with members of the closely related genus Ochrobactrum (Scholz et al., 2008a; Velasco et al., 1998). The IS711 element became the preferred target for general identification purposes due to its restricted occurrence in Brucella and the presence of multiple copies, allowing for unparalleled sensitivity and direct testing on clinical samples (Halling et al., 1993; Ouahrani et al., 1993). Other molecular markers such as recA (Scholz et al., 2008a), omp2 (Leal-Klevezas et al., 1995) or the $16 \mathrm{~S}-23 \mathrm{~S}$ intergenic transcribed sequence (Rijpens et al., 1996) were described to correctly identify members of the genus Brucella. Up until a few years ago, the most popular PCR assay developed for differentiating Brucella at species level was the so-called AMOS PCR (Bricker and Halling, 1994). This test is based on the insertion site of the IS711 element which is species-specific and results in a unique PCR profile for Brucella strains belonging to each of the B. abortus, B. melitensis, B. ovis and B. suis species (hence the name AMOS). However, B. canis, B. neotomae, some biovars of $B$. abortus and $B$. suis and the Brucella species isolated from marine mammals described later on, could not be detected by AMOS PCR. Novel IS711 chromosomal locations specific to marine mammal Brucella isolates have been identified allowing their identification and classification based on the same principle as AMOS PCR (Cloeckaert et al., 2003; Maquart et al., 2008; Zygmunt et al., 2010). Real-time PCR assays based on some of the genetic markers described above were later developed for Brucella species identification (Al Dahouk et al., 2007c) but these tests have the same limitations regarding $B$. suis and $B$. abortus detection. AMOS-PCR provided the basis for other multiplex PCR assays, such as the Bruce-ladder-PCR, able to successfully discriminate isolates of all six classical species and the marine mammal brucellae (Lopez-Goni et al., 2008; Mayer-Scholl et al., 2010). These tests, which are remarkably robust and require no expensive laboratory equipment, display the expected specificity at species level, except for some strains belonging to the closely related $B$. canis and B. suis species (Koylass et al., 2010). For many years, most epidemiological data was based on the division of the three most significant species, $B$. melitensis, $B$. abortus and $B$. suis, into a number of biovars. The reader is referred to a number of reviews which describe in detail how molecular techniques such as PFGE, IS711 fingerprinting, omp typing, IRS-PCR and AFLP were used to divide isolates into molecular groups that corresponded remarkably well with the classical species divisions (Moreno et al., 2002; Vizcaino et al., 2000; Whatmore, 2009). While the above tools are undoubtedly valuable, none has significant resolution at the subspecies level. The use of multilocus sequence analysis (MLSA) opens the way to detailed characterization of the global population structure of Brucella (Whatmore et al., 2007). These analyses confirmed the status of the classical species as distinct genetic entities, began to index intra-species diversity and relate this to historical biovar designations, and provided a framework for the placement of atypical or emerging Brucella isolates 
(De et al., 2008; Schlabritz-Loutsevitch et al., 2009; Tiller et al., 2010). Further, these analyses and the availability of more robust phylogenetic histories, allowed the identification of canonical single nucleotide polymorphisms (SNPs) that could be exploited as the basis of rapid diagnostic tests. A number of SNP-based assays have recently been described that can rapidly identify Brucella isolates to the species level (Foster et al., 2008; Gopaul et al., 2008, 2010), identify vaccine strains (Gopaul et al., 2010) or even identify to biovar level where biovars reflect true genetic groups (Fretin et al., 2008). A further major recent genome-driven advance has been the identification and exploitation of tandem DNA repeats as typing tools. These repeats have been exploited in many bacteria to develop a new generation of VNTR (Variable Number of Tandem Repeat) based typing approaches but are likely to prove particularly valuable in Brucella which previously lacked any epidemiological tool with adequate resolution to facilitate reliable epidemiological trace-back (Bricker et al., 2003; Le Fleche et al., 2006; Whatmore et al., 2006). Both MLSA and VNTR based analyses question the validity of some of the biovars established by classical microbiological typing, particularly those of B. melitensis (Al Dahouk et al., 2007a; Whatmore et al., 2007). Such analysis applied to local epidemiological scenarios shall allow progress in a number of areas previously hampered by the lack of tools with adequate discriminatory capacity. Application of these approaches should ultimately allow rapid detection of nationally or internationally dispersed clusters, detection of transmission chains, detection of new and emerging strains and trace-back to sources of outbreaks. The ability of VNTR analysis to link genotypes to background epidemiological data should also facilitate the identification of risk factors and help understand differential virulence or pathogenic properties of individual genotypes. VNTR has recently proven highly efficient in confirming laboratory or other professionally acquired infections (Marianelli et al., 2008; Valdezate et al., 2010), in distinguishing relapse from re-infection (Al Dahouk et al., 2005a; Kattar et al., 2008) in characterizing outbreaks (Lucero et al., 2010; Valdezate et al., 2007), in identifying associations of different genotypes with different pathogenic profiles (Nockler et al., 2009), and in assessing the stability of vaccine preparations (Garcia-Yoldi et al., 2007).

\section{Animal brucellosis vaccines at the beginning of the 21st century}

Successful eradication programs have always been costly, long, and hard to carry through. The difficulties in controlling and eradicating brucellosis reflect from a variety of issues. Clearly, the most important one is the animal management conditions (extensive breeding, transhumance, coexistence of several livestock species, etc.). Most often, endemic areas are in countries with marked structural weaknesses, an aggravating circumstance since efficient use of current vaccines requires proficient veterinary services. This requirement relates in part to some of the limitations of currently available brucellosis vaccines, and it seems likely that a perfect vaccine could greatly facilitate control and eradication. The perfect brucellosis vaccine should: (1), trigger a solid and life-lasting immunity; (2), protect against infection by Brucella species other than those typical of a given host; (3), be innocuous regardless of the physiological state of the animal; (4), be effective in a single dose; (5), not interfere with serological diagnostic tests; (6), not be virulent for humans or carry resistance to antibiotics; (7), not be shed in the environment; (8), be stable; and (9), be affordable. Indeed, some of these requirements have become apparent only after using the classical brucellosis vaccines for more than half a century. Here, we review briefly to what extent those requirements have been met and the approaches followed to solve some of the problems.

Researchers working on brucellosis vaccines in the past century progressively realized that killed vaccines were inferior to attenuated ones. Moreover, work with streptomycin-dependent B. melitensis mutants (see below) established that the ability to multiply in the host before clearance was a condition necessary to trigger protective immunity. Indeed, the two best vaccines developed in the past century (B. abortus S19 and B. melitensis Rev 1) are both attenuated (live) vaccines with a certain degree of residual virulence. Strain 19 is used in cattle and Rev 1 in goats and sheep, not only against $B$. melitensis but also against $B$. ovis in the latter ruminants. S19 is the result of accidental attenuation caused by prolonged laboratory storage under inadequate conditions (Nicoletti, 1990) and carries multiple genetic defects which, in most cases, are difficult to relate to attenuation (Crasta et al., 2008). Rev 1 is a revertant of a streptomycin-dependent mutant with a known ribosomal mutation (Cloeckaert et al., 2002) and possibly other genetic defects. Both vaccines carry a smooth (S) lipopolysaccharide (S-LPS) with an O-polysaccharide similar to that of the wild type brucellae.

In controlled experiments, a single dose of Rev 1 induces $80-100 \%$ protection against challenges infecting $100 \%$ of unvaccinated controls (Barrio et al., 2009). It has a low cost ( $5 €$ cents per dose when applied conjunctivally). Limitations of this vaccine are the abortifacient effect if applied during pregnancy, interference in serological diagnosis, virulence for humans and resistance to streptomycin and tendency to dissociate into ineffective rough [R] mutants. These limitations can be partially overcome by vaccinating animals conjunctivally when they are less than 4 months old which reduces greatly the interference in serological diagnosis and avoids vaccine-induced abortions; a minimal personal protection makes Rev 1 vaccination safe; and there are well-established quality control protocols. Rev 1 has been crucial wherever B. melitensis eradication has been achieved and, moreover, vaccination with Rev 1 is economically sound (Zinsstag et al., 2007). Since cattle may become infected by B. melitensis (and by some B. suis biovars), it has been suggested that Rev 1 could be used in these ruminants. However, the protective efficacy against $B$. melitensis, innocuousness and safety of Rev 1 in cattle is not known. $B$. melitensis infections in cattle can be controlled with the help of S19 (Debagues et al., 1991) but there is a paucity of studies with regard to B. suis.

With the exception of a handful of countries with favorable geographical and management conditions, all successful programs in cattle have used S19. In controlled 
experiments, the rate of protection is adequate in most cases (Nicoletti, 1990). Like Rev 1 in sheep, the choice of the vaccination route and vaccine dose is of paramount importance. Subcutaneously, standard S19 doses generate immune responses interfering in diagnostic tests and may induce abortions if applied during pregnancy and genital lesions in males. Moreover, a small proportion of animals may develop subclinical infections and shed the vaccine. Conjunctival vaccination with reduced doses when animals are less than 4 months old avoid the abortions as well as the serological interference and udder infections. It is not known whether this route and doses make S19 safe in males, a point that would be worth investigating. Conjunctival vaccination is also adequate for vaccinating adult cattle since abortions and milk shedding are reduced to less than $1 \%$. This vaccine is very economical (about $7 €$ cents per individual dose), carries no antibiotic resistance and, although less virulent for humans than Rev 1, also requires a minimal individual protection. Quality control is necessary and there are well-established protocols for this.

Despite their limitations, S19 and Rev 1 have been successfully used in some developed countries to eradicate brucellosis. However, their use in eradication programs poses the problem of distinguishing infected from vaccinated animals in serological tests. Although it is important to stress that this problem is of little or no significance in countries unable to implement testing and slaughtering programs, this has been considered the major drawback of these vaccines. Therefore, alternative vaccines devoid of diagnostically significant epitopes or antigens have been investigated in detail.

S-LPS is the most important antigen in infections by $S$ brucellae and the serologically immunodominant epitopes are carried in its $\mathrm{O}$-polysaccharide section. The LPS of $\mathrm{R}$ mutants (R-LPS) lacks the O-polysaccharide and carries only the core oligosaccharide-lipid A sections. Therefore, the use of $\mathrm{R}$ mutants as vaccines should minimize the serological interference. Although straightforward, this approach has some potential problems. First, the O-polysaccharide is critical for Brucella virulence and $\mathrm{R}$ mutants may be over attenuated and induce insufficient protection. Secondly, it is known that ruminants vaccinated with $R$ vaccines develop antibodies to the $O$-polysaccharide when exposed to virulent S brucellae (Barrio et al., 2009; Moriyon et al., 2004). Thus, healthy vaccinated animals in endemic areas may be not so readily differentiated by S-LPS tests from the infected ones. A third limitation of $R$ vaccines is due to the exposure of core epitopes (shared by the $S$ and R-LPS) in some serological tests. In those that use S Brucella cells (rose Bengal and complement fixation tests), these epitopes are not exposed and antibodies of $\mathrm{R}$ specificity are not detected. However, core epitopes become exposed upon adsorption of S-LPS to plastics and are also present and accessible in the polysaccharides obtained by acid hydrolysis of S-LPS. Thus, immunization with Brucella $\mathrm{R}$ mutants generates antibodies reacting in immunosorbent assays or in fluid phase assays that use S-LPS or hydrolytic polysaccharides (several indirect or competitive ELISAs and the fluorescence polarization assay) (Barrio et al., 2009). These limitations have been confirmed using both spontaneous $\mathrm{R}$ mutants and genetically designed $\mathrm{R}$ vaccines.
B. abortus RB51 is an R mutant obtained by passage on media with rifampin and penicillin. It carries a mutation in the O-polysaccharide gene $w b o A$ but also other and unknown genetic defects. Concerning protection, controlled experiments show that RB51 is inferior to S19 (Moriyon et al., 2004). Possibly because of this, repeated RB51 vaccination has been used by some researchers (Herrera et al., 2008; Herrera-Lopez et al., 2010; Moriyon et al., 2004). However, no controlled experiment has addressed the usefulness of these protocols, and the results of field observations are unclear (Blasco and Moriyon, 2005). As expected, RB51 does not elicit significant amounts of antibodies to the O-polysaccharide so that its interference in brucellosis tests that use S Brucella suspensions is minimal. However, the antibodies induced by RB51 are detected in those tests apparently specific for $S$ brucellae where S-LPS core epitopes are accessible (see above). RB51 can induce abortions and can be excreted (Moriyon et al., 2004; Yazdi et al., 2009), and its use should be limited to non-pregnant animals. Since RB51 is more attenuated, it should be less dangerous than S19, and only very few human cases have been described (Ashford et al., 2004; Villarroel et al., 2000). However, the number of unreported human cases might be higher because the absence of anti-O-polysaccharide antibodies makes RB51 infections undetectable in standard laboratory tests for human brucellosis. Therefore, adherence to biosafety practices should not be abandoned when using RB51. The resistance to rifampin is an additional drawback of RB51 because this antibiotic is often preferred over streptomycin or gentamicin (in all cases combined with doxycyclin) for treatment. To the best of our knowledge, there are no internationally accepted criteria for quality control of RB51. A typical market price in the European Union is $1.2 €$ per dose, which is exceedingly high for developing economies. Although introduced over 12 years ago, no country using RB51 has eradicated cattle brucellosis although success has recently been suggested in the Azores, Portugal (Martins et al., 2009). However, such field observations are either contradictory (Moriyon et al., 2004) or controversial because of the implementation of additional control measures and the absence of appropriate control groups (Blasco and Moriyon, 2005, 2010; Martins et al., 2009, 2010). RB51 does not protect sheep against either B. melitensis or B. ovis (Moriyon et al., 2004). Furthermore, it has been tested in water buffaloes (Fosgate et al., 2003), pigs (Stoffregen et al., 2006), bisons (Davis and Elzer, 2002) and cervids (Cook et al., 2002) with negative results.

Various other vaccine candidates (LPS defect mutants, protein deploid mutants, etc.) have been tested in animal experiments or have not gone beyond laboratory models.

Given the successful eradication of B. abortus and $B$. melitensis in some developed countries, it may be asked whether this research is necessary at all. The answer is that the organization and favorable environmental conditions found in these countries were a decisive factor in eradication. Those conditions are unlikely to be reached soon or even be possible in many areas where brucellosis is endemic and control and eradication can be facilitated only by a perfect brucellosis vaccine. Moreover, vaccines for reindeers, water buffaloes, yaks, camels, and swine, all 
susceptible animals that are important in the economies of many countries, are still missing. Last but not least, the necessary vaccines can only be developed on the basis of a better understanding of the pathogen and its interaction with the immune system.

\section{Epidemiology of animal brucellosis}

Prevalence and epidemiology of brucellosis in livestock production has been described in many developing countries as seen by the number of reports generated in the past 10 years. Cattle seroprevalence estimates have been observed to range between 3 and 15\% (Ghanem et al., 2009; Haileselassie et al., 2010; Jergefa et al., 2009; Muma et al., 2006). Factors influencing prevalence include production systems, agro-ecological zones, husbandry practices, contact with wildlife, management factors (Matope et al., 2010; Muma et al., 2007b; Omer et al., 2000). In cattle, brucellosis continues to contribute to economic losses associated with abortions, infertility and prolonged calving to conception intervals. The odds of abortion in Brucellainfected cattle have been observed to range between 3 and 4 in exposed cows compared to non-exposed (Muma et al., 2007a; Schelling et al., 2003). Generally, in most developed countries, test-and-slaughter programs, together with compensation for farmers, accreditation and financial incentives for disease-free herds, allowed the achievement of a status close to eradication of brucellosis in livestock and, consequently, in humans (Saegerman et al., 2010).

In cattle, the infection is predominantly caused by $B$. abortus, and is usually detected in pregnant females through abortions. The removal of sanitary barriers and the liberalization of exchanges in accordance with the World Trade Organization Agreement require the harmonization of the brucellosis health status among countries in order to eliminate the risk of contamination of a country with a favorable health status through importation of live animals and animal products from a country with a lower health status. In 2008, 12 EU member states were Officially Brucellosis Free $(\mathrm{OBF})$ in cattle, as well as in sheep and goats. In 2008, 15 non-OBF member states reported bovine cases of brucellosis (herd prevalence equal to $0.12 \%$ ). The situation is less favorable in Southern European countries but is still below 1\% (European Food Safety Agency, 2010b). Because brucellosis has public health and international trade implications, all member states have an interest in obtaining and in maintaining this officially free status.

Cases of cross-infections with $B$. melitensis were observed in herds mixed with sheep and goat flocks in southern Europe (Verger et al., 1989) and are regularly reported in the middle east where it has become an emerging veterinary and public health problem (Samaha et al., 2008).

Special emphasis is given here to $B$. suis biovars 1,2 and 3 and $B$. abortus in pigs because of their propable impact on human health in the future. B. suis biovars 1 and 3 are found worldwide in most areas where pigs are kept. They affect both sexes of swine causing infertility, abortion, orchitis and lesions of bones and joints. The prevalence is generally low except in parts of South America and South East Asia.
Within the EU, the epidemiological situation of brucellosis in pigs varies. Some countries are free from the disease, others report sporadic outbreaks and some report infections as an emerging problem. Available epidemiological evidence shows that $B$. suis biovar 2 is the most common agent, but biovars 1 and 3 can also occur. There is also evidence suggesting that wild boars currently remain the main source of infection for domestic pigs because several outbreaks of $B$. suis occurred in outdoor rearing farms. An enzootic $B$. suis biovar 2 was described in the nineties in Belgium (Godfroid et al., 1994) and since then brucellosis in wild boars has been described in wild boars and in hares (Lepus europeaus) in several member states of the European Union (European Food Safety Agency, 2010a). In the south of the USA (Olsen and Tatum, 2010) and in Australia (Irwin et al., 2010) populations of feral swine are heavily infected with $B$. suis biovar 1 . Infections with $B$. suis in humans occur in people handling pigs on farms and during slaughtering and processing, including the hunting of feral swine. Recently, it has been shown in South Carolina, USA, that feral pigs were infected with $B$. abortus wildtype, S19 and RB51 vaccine strains besides $B$. suis biovar 1 (Stoffregen et al., 2007). The importance of this finding lies in that pigs were for the first time demonstrated to act as reservoir host of $B$. abortus in the absence of contact with cattle for more than 25 years. $B$. suis biovar 1 has been isolated from pigs and humans in all central American countries (Moreno, 2002). Isolation of $B$. suis biovar 1 has been reported in Mexico (Luna-Martinez and Mejia-Teran, 2002), in central Venezuela (Vargas, 2002), in Paraguay (Baumgarten, 2002) and in Brazil, where it is the second most prevalent Brucella infection in livestock (Poester et al., 2002). In Argentina, $B$. suis biovar 1 is frequently isolated from pigs (Samartino, 2002) but has also been isolated from people and cattle (Lucero et al., 2008). As for B. melitensis infection in cattle, $B$. suis biovar 1 infection in cattle is an emerging veterinary and public health problem, even more so considering that the mammary gland is a preferred site for $B$. suis biovar 1 localization in cattle (Olsen and Hennager, 2010).

Only B. suis biovar 2 has been isolated in pigs in India (Renukaradhya et al., 2002). Isolation of B. suis biovars 1 and 3 (never biovar 2) has been reported from pigs and humans in 21 provinces of China (Deqiu et al., 2002). In Africa, the disease is believed to occur sporadically. In Egypt, $B$. suis biovar 1 is present, although often unrecognized and unreported (Refai, 2002). A number of sub-Saharan African countries officially reported porcine brucellosis to the OIE. However, the biovars involved are not mentioned in the available literature (McDermott and Arimi, 2002). Moreover, to the best of our knowledge, no isolation of $B$. suis has been reported from sub-Saharan Africa, neither from domestic nor from wild or feral pigs. This highlights that the epidemiological situation of brucellosis in domestic, feral and wild suidae in sub-Saharan Africa is virtually unknown. In view of the essentially negative impact of almost all "naturalized" pig populations on their environments, the Pigs and Peccaries Specialist Group of the UICN recommended in 1993 that: "wild pigs or peccaries of any species or subspecies (or their domestic or feral derivatives) should never be deliberately released to range freely outside their known, recent and original distribution, and 
that all possible efforts should be made to prevent the accidental naturalization of domestic or wild populations of these animals. All existing naturalized populations should be regarded as exotic pests which should be controlled, reduced in numbers or eradicated wherever possible and appropriate". It is worth to note that these recommendations were formulated without reference to infectious diseases. Given the widespread infection of suidae with Brucella spp. and in the context of the "One Health" concept, we fully support these recommendations which are aiming at reducing opportunities for $B$. suis and possibly $B$. abortus to "jump" between domestic, feral and wild suidae on one hand and humans on the other hand.

\section{Epidemiology and clinical manifestations of human brucellosis}

Currently, only three nomen species of the genus Brucella have an essential impact on public health, i.e., in order of their significance B. melitensis, B. abortus, and B. suis.

Although human brucellosis is the most common bacterial zoonotic infection worldwide it is still a regionally neglected disease (Pappas et al., 2006b). Human brucellosis is known to be highly endemic in the Mediterranean basin, Middle East, Western Asia, Africa, and South America (Pappas et al., 2006b). Although animal brucellosis has been brought under control in several industrialized countries, human brucellosis occurs sporadically in individuals who acquire the infection abroad or by illegally imported ingestion of unsafe animal products and in occupationally exposed groups (Al Dahouk et al., 2005b, 2007b). In 2008, a total of 619 confirmed human brucellosis cases were reported in the European Union (EU) ( 0.1 case per 100,000 inhabitants). The highest incidence was recorded in those member states not officially free from bovine and ovine/caprine brucellosis (Greece, Italy, Portugal and Spain). At EU level, a statistically significant decreasing trend was observed during the five-year period 2004-2008. The peak of reported cases was observed in spring and summer (European Food Safety Agency, 2010b).

Childhood brucellosis (B. melitensis) in the United States is now an imported disease, primarily from Mexico. A retrospective study related to 20 patients who received a diagnosis of brucellosis over a period of 13 was performed years. Ninety-five percent of the patients had a recent history of either travel to Mexico or ingestion of unpasteurized milk products from Mexico. Fever was an initial complaint in $80 \%$ of the patients, and $50 \%$ of the patients presented with arthritis (Shen, 2008).

Studies conducted in North Africa and in the MiddleEast reported the occurrence of human brucellosis attributed to the presence of $B$. melitenis in livestock (AlAni et al., 2004; Jennings et al., 2007) while in sub-Saharan African B. abortus is mainly implicated (Hendricks et al., 1995; Swai and Schoonman, 2009). Human brucellosis is often misdiagnosed in developing countries (Paul et al., 1995 ) resulting in under reporting of cases. A study in Tanzania showed that medical professionals, especially those in rural areas had poor knowledge of zoonotic diseases (John et al., 2008). In areas where B. abortus is a major problem in cattle, seroprevalence rates in humans are esti- mated to be in the range of $1-5 \%$ (Schelling et al., 2003; Swai and Schoonman, 2009) but in areas where B. melitensis is endemic (mainly in the middle East) higher prevalence rates have to be expected (Pappas et al., 2006b). The countries with the highest incidence of human brucellosis are Saudi Arabia, Iran, Palestinian Authority, Syria, Jordan and Oman (Pappas et al., 2005). Consumption of raw milk continue to be the major mode of exposure in developing countries (Makita et al., 2008; Pappas et al., 2006b; Swai and Schoonman, 2009).

Although Brucella can be transmitted directly and indirectly from its animal reservoir to humans, indirect transmission remains the highest overall risk and mainly occurs through the consumption of unpasteurized milk or dairy products (Godfroid et al., 2005). B. melitensis infection in cattle has emerged as a serious public health problem in some southern European countries and Israel as a result of the consumption of unpasteurized milk since $B$. melitensis is capable of colonizing the bovine udder (Banai, 2002; Ashford et al., 2004; Lamontagne et al., 2010). Moreover, in some South American countries, cattle are now believed to be more important than pigs as a source of $B$. suis biovar 1 infection for humans, because $B$. suis biovar 1 is capable of colonizing the bovine udder as B. melitensis does (Corbel, 1997). Consequently, human brucellosis is mainly food-borne but can also be an occupational infection. The incubation period of the disease varies greatly, ranging from weeks to months. The clinical onset of human brucellosis is insidious and Brucella infections often develop as fever of unknown origin. The acute stage of the disease is usually accompanied by bacteremia and spreading of the organism to various organ systems, mainly to reticuloendothelial tissues. Hence, human brucellosis is a systemic infectious disease of varying clinical manifestations. Acute brucellosis is characterized by nonspecific systemic signs and clinical symptoms consistent with a flu-like or septicemic illness, i.e., fever, fatigue, malaise, weight loss, headaches, arthralgia, myalgia, chills, and sweats. Clinical manifestations may comprise osteoarticular, dermal, gastrointestinal, respiratory, cardiovascular, and neurologic disorders mimicking many other infectious and non-infectious diseases. Since Brucella survives and replicates in the mononuclear phagocytic system, chronic courses, focal complications, and relapses frequently occur. Life-threatening focal complications are Brucella endocarditis and neurobrucellosis but the overall case fatality rate is low (less than $1 \%$ ).

In general, inadequate treatment is responsible for severe and debilitating chronic courses and long-term sequelae. Hence, the basic therapeutic goal is not only to control acute illness but also to prevent complications and relapses. Use of at least two synergistic antibiotics, including doxycycline, rifampin, streptomycin (or other aminoglycosides) or trimethoprim-sulfamethoxazole (cotrimoxazole), is therefore a must in prolonged chemotherapeutic regimens. Internationally two different treatment options are recommended. The combination of oral doxycycline $100 \mathrm{mg}$ twice a day and rifampin 600-900 mg/day (15 mg/kg/day) in a single oral dose over a 6-week course shows fewer adverse effects than a combination including streptomycin $1 \mathrm{~g}$ intramuscularly once a day for 2 
weeks or an alternative aminoglycoside, instead of the administration of rifampin. However, the latter treatment is characterized by lower relapse rates (Ariza et al., 2007; Corbel, 2006). For a successful therapy of focal complications and chronic courses triple or tetra combinations of the antimicrobial drugs mentioned and longer treatment courses ( $>45$ days) are essential.

Few cases of brucellosis in humans caused by B. canis have been described (Lucero et al., 2010; Nomura et al., 2010). However, canine brucellosis in man might be underdiagnosed due to a low perception of the disease and a lack of valid serological tests. Human infections by marine mammal strains have a severe course but are reported only rarely (Brew et al., 1999; McDonald et al., 2006; Sohn et al., 2003). The clinical importance of $B$. inopinata and the atypical Brucella strain (BO2) closely related to $B$. inopinata is still unclear despite the fact that both agents have been isolated from diseased humans (De et al., 2008; Scholz et al., 2010). Little is also known about the human pathogenicity of $B$. microti but in experimental cellular and murine models of infection $B$. microti exhibited a significantly higher virulence than other Brucella species (de Bagues et al., 2010).

\section{Control of brucellosis}

In the developed world, control of animal brucellosis has been successfully achieved through the combination of vaccination and test-and-slaughter programs and human brucellosis through milk pasteurization (McDermott and Arimi, 2002; Pappas et al., 2006b), coupled with effective disease surveillance and animal movement control. In developing countries, however, control by test-andslaughter is hardly achievable because of limited resources to indemnify farmers whose animals are slaughtered during such screening programs (McDermott and Arimi, 2002). Since animals are not often kept as business enterprises, the off takes are often low (Muma et al., 2009). Thus animals tend to live long resulting in emotional attachment of the farmers to their animals. It has been suggested that any disease control strategies need to take into account the need and perceptions of the communities (Marcotty et al., 2009). While occupational exposure may be considered as a major mode of transmission, consumption of infected milk products from infected animals remains a major route of transmission even in non-endemic countries like Germany where consumption of Brucella contaminated products accounted for infections acquired abroad (Al Dahouk et al., 2005c).

In a study done in Kampala, urban residents who had no contact with livestock were at risk of being Brucella infected an exposure attributed to consumption of raw milk products purchased from rural and peri-urban area (Makita et al., 2008). Since consumption of raw milk continues to be a major mode of exposure as demonstrated in several studies (Almuneef et al., 2003; Makita et al., 2008), pasteurization or boiling of milk and milk products, is likely to reduce human infections. A survey conducted in Kenya showed that boiling of milk reduced the risk of exposure to Brucella (Arimi et al., 2005). Other factors contributing to exposure included ignorance of risk of Brucella infection (Marcotty et al., 2009). In some cases, perceived enhanced nutritional qualities, taste, and health benefits have all been advocated as reasons for increased interest in raw milk consumption. Therefore, involvement of anthropologists and social workers will become increasingly important in successful control of human brucellosis (Marcotty et al., 2009).

Risk assessment is a tool that should be advocated to the World Trade Organization in the context of trade policy (Agreement on the application of sanitary and phytosanitary measures). The methodology might also be used to assist in the choice of an appropriate national response strategy following an incursion of a reemerging disease. The choice of a strategy in the affected regions should be made after an independent, scientific and collective assessment where the range and magnitude of consequences of implementing or not, measures or surveillance programs of all susceptible domestic livestock (and possibly wildlife) are considered (scenario analysis). Such a risk assessment should be performed taking into account current scientific knowledge, the particular local situation and uncertainties about the parameters used in the model. In addition, decision trees are often used to clarify the path to appropriate measures. Analysis includes evaluation of several parameters such as the probability of exposure to an infectious agent as well as the cost and consequences of the specific measure application. Furthermore, animal movement controls may need to be considered (Hadorn and Stark, 2008). To illustrate this section, we present two examples for bovine brucellosis. The first one is dedicated to the development of a quantitative risk assessment for the importation of brucellosis-infected breeding cattle into an EU member state from other selected EU member states (Jones et al., 2004) and the second one to the development of a simulation model of brucellosis spread in a cattle population of a member state, or region of it, under several testing regimes (England et al., 2004). The two examples are from Great Britain (GB), declared OBF since 1993. As required by the EU legislation, at least $20 \%$ of both beef and dairy cattle of more than 24 months of age are to be tested. As GB gained its OBF status, the necessity of such a high testing level was naturally questioned. In the first example (Jones et al., 2004), a quantitative risk-assessment model was developed to determine the annual risk of importing brucellosis-infected breeding cattle into GB from Northern Ireland and the Republic of Ireland (who exported the largest number of cattle into GB and were not brucellosis free during the development of the assessment in 2000). With this assessment, the risks of importing bovine brucellosis every 2.63 and 3.23 years were found, respectively from Northern Ireland and from the Republic of Ireland. Consequently, policy-makers introduced post-calving testing for all cattle imported into GB herds. A similar decision has been applied in Belgium since 2003 after a qualitative risk assessment and experts' opinion (Saegerman et al., 2010). The risk estimates are sensitive to the level of uncertainty associated with the test sensitivities and to the assumed proportion of animals originating from OBF herds missed during routine surveillance (Saegerman et al., 2010). In the second example (England et al., 2004), a simulation model to determine the rate of brucellosis spread under a variety of testing regimes was developed. If brucellosis was imported, the reduction of testing level would 
have a major negative effect on the spread of infection between dairy herds. For beef herds, this reduction would have a lesser effect. In addition, the notification of an abortion is a very important additional mean of surveillance to reduce the disease spread. Consequently, policy-makers decided not to reduce the level of testing and to actively promote abortion notification.

Most reemerging infectious diseases, like bovine brucellosis, cause difficulties for veterinary authorities that are confronted not only with animal but also with public health issues. Moreover these diseases are especially challenging because they are initially rare and therefore difficult to detect. Despite the low prevalence of an emerging infectious disease at the time of its incursion, the surveillance system should be able to detect its presence as early as possible. Any delay in the detection of the disease hinders the anticipated result of control measures. Indeed, without early detection, emergence can pass unperceived as long as a factor of amplification does not reveal it. Detection is often too late from the risk control point of view. In particular if the disease, before expressing itself clinically, passes through an incubation period, a delayed detection allows its diffusion into the sensitive population and outside the contaminated areas by means of animal sale. Improvement of identification tools and swiftness of detection are essential (Saegerman, 2006).

The key point for early detection is the sensitivity of the surveillance system, i.e., the ability to detect an outbreak as soon as possible (Hadorn and Stark, 2008). A review on the different brucellosis tests has recently been published (Godfroid et al., 2010). In addition, because of decreasing resources for animal health surveillance, current surveillance strategies need to be evaluated and optimized in terms of surveillance performance in relation to costs. Scenario trees were designed for bovine brucellosis (Martin et al., 2007). For an OBF EU member state like Belgium, preliminary results indicated, that a decrease of serological sampling pressure by a factor 25 , do not influence the sensitivity of the surveillance system. Scenario tree analysis also stressed the importance of the abortion testing and the test at purchase (in case of importation). This study demonstrated how useful these models can be as tools for the implementation of a 'risk-based' surveillance program with an acceptable statistical confidence level, in response to European and international standards.

All US states are classified Free of $B$. abortus in cattle. However, infection remains in Greater Yellowstone Area (GYA) wildlife with occasional spill-over into livestock. Brucellosis-infected cattle herds have been detected in Idaho (December 2009), Wyoming (June 2008), and Montana (May 2007 and June 2008). The most likely source of infection in these herds is believed to be infected freeranging elk (Van Campen and Rhyan, 2010). Control of brucellosis among domestic animals in the United States faces continued pressure from the presence of brucellosis in US wildlife and also in domestic livestock (especially cattle and goats) across the southern border in Mexico where eradication programs of bovine brucellosis (B. abortus infection) have made substantial progress whereas control of brucellosis among domestic goat herds ( $B$. melitensis infection) has proven more challenging (Glynn and Lynn, 2008).
According to the World Organisation for Animal Health (OIE), bovine brucellosis is a reportable zoonosis and is of considerable socioeconomic concern. It is of major importance in the international trade of animals and animal products. Because brucellosis has public health and international-trade implications, all member states of the OIE have an obligation of reporting. This information is available at the World Animal Health Information Database (WAHID) Interface (http://web.oie.int/wahis/ public.php?page=home). The common concept of zoonosis in the modern world is changing and veterinary public health needs to do likewise. Veterinary public health needs to be more than a reactive response to human needs; it also needs to have a proactive input. Control of brucellosis in developing nations is no longer a local problem but should be considered as global challenge since any global citizen can easily become exposed as they travel abroad (Al Dahouk et al., 2005c; Godfroid et al., 2005). Other challenges to be faced in controlling brucellosis will include the control of the expanding wildlife reservoir, the control of the wildlife-livestock interface and the development of control strategies that are acceptable to communities and take into account anthropological factors (Marcotty et al., 2009).

In the upcoming period it would be beneficial to improve the brucellosis awareness, diagnostic capabilities and the surveillance in livestock, wildlife and humans. It is of primary importance to isolate strains in order to get a deeper insight into transmission modes and if an animal species acts as a spill over host or a true reservoir. It is worth mentioning that there are very few reports on the isolation of Brucella strains in sheep and goats in sub-Saharan Africa. Surprisingly, only B. abortus has been isolated from sheep in Nigeria (Ocholi et al., 2004), whereas B. melitensis has been isolated from sheep and camel in Western Darfour, Soudan (Musa et al., 2008; Musa and Jahans, 1990) Interestingly, different biovars of $B$. abortus were also isolated from camel, suggesting multiple sources of infections from their preferential hosts (Musa et al., 2008). It is important to reiterate that the isolation of $B$. suis in sub-Saharan Africa has never been documented in the scientific literature, although the infection is believed to be widely spread (McDermott and Arimi, 2002).

The isolation of Brucella spp. from the animal reservoir is not a trivial enterprise. Indeed, $B$. melitensis infection in cattle and $B$. abortus infection in sheep were only reported when a source of Brucella spp. was found in its preferential host, i.e., B. melitensis in sheep and B. abortus in cattle. This suggests that $B$. melitensis infection in cattle and $B$. abortus in sheep are spill over infections and cannot establish enzootic infections. It is important to be reminded that any sound vaccination program in livestock should be implemented in reservoir hosts, not in spill over hosts, even more so in countries where resources are scarce. Whether $B$. melitensis and B. abortus are sustained infections in camels remains to be determined.

Further, accurate estimates of the impact of brucellosis on public health and animal production will attract the necessary support for resources from policy makers against the many competing needs such as malaria, HIV, and tuberculosis (Zinsstag et al., 2007). 


\section{Bio- and agroterrorism}

Brucellae are highly potent pathogens in man and animals and as such also very effective biological agents for use in biological weapons. A low infectious dose of 10 bacteria and the fact that brucellae are easily transmitted to humans via aerosols make these bacteria most attractive for military researchers (Hoover and Friedlander, 2010). Consequently B. suis was one of the first agents being weaponised (Pappas et al., 2006a). International disarmament efforts made it unlikely that biological weapons of mass destruction will be used by states' armies in modern wars nowadays. However, fears have arisen that biological weapons may be used against civilian targets by private organizations, groups or even individuals in attacks of bioterrorists. Rotz et al. (2002) made a risk assessment for a brucellosis outbreak with special respect on its influence on public health and medical infrastructure on a large scale using following criteria: public health impact, delivery potential to large populations, public perception, i.e., public fear and civil disruption, and special public health preparedness needs (Rotz et al., 2002). Brucellosis was ranked in the category B having only a lower medical and public impact (Pappas et al., 2006a; Rotz et al., 2002). It can be supposed that in countries which have successfully eradicated brucellosis, the first responders, e.g., family doctors, will not be aware of the clinical picture of the disease and that a delay in the diagnosis of the disease will result in a higher number of fatal courses. Consequently, public health (i.e., medical awareness, surveillance and laboratory diagnostic capabilities) has to be strengthened in the future in both developed and developing countries. In the field of veterinary public health, the danger arising from agroterroism (the deliberate tampering with and/or contamination of the food supply with the intent of adversely affecting the social, economic, physical, and psychological well-being of society) is of concern (Gyles, 2010). Targets may be farm animals (cattle, swine, sheep, horses, poultry and fish), field crops, processed food and storage facilities (Gyles, 2010). Countries being free from animal brucellosis may suffer from severe economic losses by the deliberate introduction of brucellosis into their bovine, caprine/ovine or porcine livestock. An attack with Brucella spp. may also be associated with severe outbreaks in the human population (Willyard, 2007).

\section{General conclusions}

Brucella is a fascinating 'stealthy' organism which is able to subvert the host immune system and whose strategies to survive and multiply in phagocytic and epithelial cells are becoming better understood. Deciphering the metabolism of Brucella will reveal pathogenic pathways used by the bacterium to survive dramatic stresses in its cellular environment. Brucellosis in its animal reservoir has only been controlled and sometimes eradicated in livestock in the developed world. Its burden to livestock and its toll to people are very important in the developing world, although not fully recognized. It is still feared that Brucella could be used as a weapon in bio- or agroterrorism. Preparedness is an issue which needs to be addressed by both the medical and the veterinary professions. Lastly brucellosis in wildlife is not controlled; new reservoir hosts and new Brucella species are discovered and baseline information is dramatically missing. It is a global responsibility to reduce opportunities for Brucella spp. to "jump" host species at the animal/environment/human interface and will need a "One Health" approach to be successful.

\section{Conflict of interest}

None.

\section{References}

Al Dahouk, S., Hagen, R.M., Nockler, K., Tomaso, H., Wittig, M., Scholz, H.C., Vergnaud, G., Neubauer, H., 2005a. Failure of a short-term antibiotic therapy for human brucellosis using ciprofloxacin-a study on in vitro susceptibility of Brucella strains. Chemotherapy 51, 352-356.

Al Dahouk, S., Le Fleche, P., Nockler, K., Jacques, I., Grayon, M., Scholz, H.C., Tomaso, H., Vergnaud, G., Neubauer, H., 2007a. Evaluation of Brucella MLVA typing for human brucellosis. Journal of Microbiological Methods 69, 137-145.

Al Dahouk, S., N+Âckler, K., Hensel, A., Tomaso, H., Scholz, H.C., Hagen, R.M., Neubauer, H., 2005b. Human brucellosis in a nonendemic country: a report from Germany, 2002 and 2003. European Journal of Clinical Microbiology \& Infectious Diseases 24, 450-456.

Al Dahouk, S., Neubauer, H., Hensel, A., Schoneberg, I., Nockler, K., Alpers, K., Merzenich, H., Stark, K., Jansen, A., 2007b. Changing epidemiology of human brucellosis, Germany, 1962-2005. Emerging Infectious Diseases 13, 1895-1900.

Al Dahouk, S., Tomaso, H., Prenger-Berninghoff, E., Splettstoesser, W.A., Scholz, H.C., Neubauer, H., 2005c. Identification of Brucella species and biotypes using polymerase chain reaction-restriction fragment length polymorphism (PCR-RFLP). Critical Reviews in Microbiology 31, 191-196.

Al Dahouk, S., N+Âckler, K., Scholz, H.C., Pfeffer, M., Neubauer, H., Tomaso, H., 2007c. Evaluation of genus-specific and species-specific real-time PCR assays for the identification of Brucella spp. Clinical Chemistry and Laboratory Medicine 45, 1464-1470.

Al-Ani, F.K., El-Qaderi, S., Hailat, N.Q., Razziq, R., Al-Darraji, A.M., 2004. Human and animal brucellosis Jordan between 1996 and 1998: a study. Revue Scientifique et Technique-Office International des Epizooties 23, 831-840.

Almuneef, M., Memish, Z.A., Al Shaalan, M., Al Banyan, E., Al-Alola, S., Balkhy, H.H., 2003. Brucella melitensis bacteremia in children: review of 62 cases. Journal of Chemotherapy 15, 76-80.

Arimi, S.M., Koroti, E., Kang'ethe, E.K., Omore, A.O., McDermott, J.J., 2005. Risk of infection with Brucella abortus and Escherichia coli O157: H7 associated with marketing of unpasteurized milk in Kenya. Acta Tropica $96,1-8$

Ariza, J., Bosilkovski, M., Cascio, A., Colmenero, J.D., Corbel, M.J., Falagas, M.E., Memish, Z.A., Roushan, M.R.H., Rubinstein, E., Sipsas, N.V., Solera, J., Young, E.J., Pappas, G., 2007. Perspectives for the treatment of brucellosis in the 21st century: The Ioannina Recommendations. PLoS Med 4, e317.

Ashford, D.A., di Pietra, J., Lingappa, J., Woods, C., Noll, H., Neville, B., Weyant, R., Bragg, S.L., Spiegel, R.A., Tappero, J., Perkins, B.A., 2004. Adverse events in humans associated with accidental exposure to the livestock brucellosis vaccine RB51. Vaccine 22, 3435-3439.

Baily, G.G., Krahn, J.B., Drasar, B.S., Stoker, N.G., 1992. Detection of Brucella melitensis and Brucella abortus by DNA amplification. Journal of Tropical Medicine and Hygiene 95, 271-275.

Baldwin, C.L., Parent, M., 2002. Fundamentals of host immune response against Brucella abortus: what the mouse model has revealed about control of infection. Veterinary Microbiology 90, 367-382.

Banai, M., 2002. Control of small ruminant brucellosis by use of Brucella melitensis Rev.1 vaccine: laboratory aspects and field observations. Veterinary Microbiology 90, 497-519.

Barrio, M.B., Grillo, M.J., Munoz, P.M., Jacques, I., Gonzalez, D., De Miguel, M.J., Marin, C.M., Barberan, M., Letesson, J.J., Gorvel, J.P., Moriyon, I., Blasco, J.M., Zygmunt, M.S., 2009. Rough mutants defective in core and $\mathrm{O}$-polysaccharide synthesis and export induce antibodies reacting in an indirect ELISA with smooth lipopolysaccharide and are less effective than Rev 1 vaccine against Brucella melitensis infection of sheep. Vaccine 27, 1741-1749. 
Baumgarten, D., 2002. Brucellosis: a short review of the disease situation in Paraguay. Veterinary Microbiology 90, 63-69.

Blasco, J.M., Moriyon, I., 2010. Eradication of bovine brucellosis in the Azores, Portugal-Outcome of a 5-year programme (2002-2007) based on test-and-slaughter and RB51 vaccination. Preventive Veterinary Medicine 94, 154-157.

Blasco, J.M., Moriyon, I., 2005. Letter to the editor. Comparative Immunology Microbiology and Infectious Diseases 28, 371-373.

Boschiroli, M.L., Ouahrani-Bettache, S., Foulongne, V., MichauxCharachon, S., Bourg, G., lardet-Servent, A., Cazevieille, C., Liautard, J.P., Ramuz, M., O'Callaghan, D., 2002. The Brucella suis virB operon is induced intracellularly in macrophages. Proceedings of the National Academy of Sciences of the United States of America 99, 1544-1549.

Brew, S.D., Perrett, L.L., Stack, J.A., MacMillan, A.P., Staunton, N.J., 1999. Human exposure to Brucella recovered from a sea mammal. Veterinary Record 144, 483.

Bricker, B.J., Ewalt, D.R., Halling, S.M., 2003. Brucella 'HOOF-Prints': strain typing by multi-locus analysis of variable number tandem repeats (VNTRs). BMC Microbiology, 3.

Bricker, B.J., Halling, S.M., 1994. Differentiation of Brucella-Abortus-Bv-1, Brucella-Abortus-Bv-2, and Brucella-Abortus-Bv-4, Brucella-Melitensis, Brucella-Ovis, and Brucella-Suis-Bv-1 by PCR. Journal of Clinical Microbiology 32, 2660-2666.

Brown, S.A., Palmer, K.L., Whiteley, M., 2008. Revisiting the host as a growth medium. Nature Reviews Microbiology 6, 657-666.

Cloeckaert, A., Grayon, M., Grepinet, O., 2002. Identification of Brucella melitensis vaccine strain Rev.1 by PCR-RFLP based on a mutation in the rpsL gene. Vaccine 20, 2546-2550.

Cloeckaert, A., Grayon, M., Grepinet, O., Boumedine, K.S., 2003. Classification of Brucella strains isolated from marine mammals by infrequent restriction site-PCR and development of specific PCR identification tests. Microbes and Infection 5, 593-602.

Cook, W.E., Williams, E.S., Thorne, E.T., Kreeger, T.J., Stout, G., Bardsley, K., Edwards, H., Schurig, G., Colby, L.A., Enright, F., Elzer, P.H., 2002. Brucella abortus strain Rb51 vaccination in elk I. Efficacy of reduced dosage. Journal of Wildlife Diseases 38, 18-26.

Corbel, M.J., 2006. In: Corbel, M.J., Elberg, S.S., Cosivi, O. (Eds.), Brucellosis in Humans and Animals. World Health Organization, Geneva, Switzerland, Ref Type: Report.

Corbel, M.J., 1997. Brucellosis: an overview. Emerging Infectious Diseases $3,213-221$.

Crasta, O.R., Folkerts, O., Fei, Z.J., Mane, S.P., Evans, C., Martino-Catt, S., Bricker, B., Yu, G.X., Du, L., Sobral, B.W., 2008. Genome sequence of Brucella abortus vaccine strain S19 compared to virulent strains yields candidate virulence genes. Plos One, 3.

Davis, D.S., Elzer, P.H., 2002. Brucella vaccines in wildlife. Veterinary Microbiology $90,533-544$

de Bagues, M.P.J., Ouahrani-Bettache, S., Quintana, J.F., Mitjana, O., Hanna, N., Bessoles, S., Sanchez, F., Scholz, H.C., Lafont, V., Kohler, S., Occhialini, A., 2010. The new species Brucella microti replicates in macrophages and causes death in murine models of infection. Journal of Infectious Diseases 202, 3-10.

De, B.K., Stauffer, L., Koylass, M.S., Sharp, S.E., Gee, J.E., Helsel, L.O., Steigerwalt, A.G., Vega, R., Clark, T.A., Daneshvar, M.I., Wilkins, P.P., Whatmore, A.M., 2008. Novel Brucella strain (BO1) associated with a prosthetic breast implant infection. Journal of Clinical Microbiology $46,43-49$.

Debagues, M.P.J., Marin, C.M., Blasco, J.M., 1991. Effect of antibiotictherapy and strain-19 vaccination on the spread of Brucella-Melitensis within an infected dairy-herd. Preventive Veterinary Medicine 11, 17-24.

Deqiu, S., Donglou, X., Jiming, Y., 2002. Epidemiology and control of brucellosis in China. Veterinary Microbiology 90, 165-182.

Dozot, M., Poncet, S., Nicolas, C., Copin, R., Bouraoui, H., Maze, A., Deutscher, J., De Bolle, X., Letesson, J.J., 2010. Functional characterization of the incomplete phosphotransferase system (PTS) of the intracellular pathogen Brucella melitensis. Plos One, 5.

England, T., Kelly, L., Jones, R.D., MacMillan, A., Wooldridge, M., 2004. A simulation model of brucellosis spread in British cattle under several testing regimes. Preventive Veterinary Medicine 63, 63-73.

European Food Safety Agency, 2010a. Scientific opinion of the panel on Animal Health and Welfare (AHAW) on a request from the commission on porcine brucellosis (Brucella suis). EFSA 1144, 1-112.

European Food Safety Agency, 2010b. The community summary report on trends and sources of zoonoses and zoonotic agents and food-borne outbreaks in the Europan Union in 2008. EFSA Journal 8, 1496.

Fosgate, G.T., Adesiyun, A.A., Hird, D.W., Johnson, W.O., Hietala, S.K., Schurig, G.G., Ryan, J., Diptee, M.D., 2003. Evaluation of brucellosis
RB51 vaccine for domestic water buffalo (Bubalus bubalis) in Trinidad. Preventive Veterinary Medicine 58, 211-225.

Foster, G., Osterman, B.S., Godfroid, J., Jacques, I., Cloeckaert, A., 2007. Brucella ceti sp. nov and Brucella pinnipedialis sp. nov. for Brucella strains with cetaceans and seals as their preferred hosts. International Journal of Systematic and Evolutionary Microbiology 57, 2688-2693.

Foster, J.T., Okinaka, R.T., Svensson, R., Shaw, K., De, B.K., Robison, R.A., Probert, W.S., Brown, W.D., Keim, P., 2008. Real-time PCR assays of single-nucleotide polymorphisms defining the major Brucella clades. Journal of Clinical Microbiology 46, 296-301.

Fretin, D., Fauconnier, A., Kohler, S., Halling, S., Leonard, S., Nijskens, C., Ferooz, J., Lestrate, P., Delrue, R.M., Danese, I., Vandenhaute, J., Tibor, A., DeBolle, X., Letesson, J.J., 2005. The sheathed flagellum of Brucella melitensis is involved in persistence in a murine model of infection. Cellular Microbiology 7, 687-698.

Fretin, D., Whatmore, A.M., Al Dahouk, S., Neubauer, H., Garin-Bastuji, B., Albert, D., Van Hessche, M., Menart, M., Godfroid, J., Walravens, K., Wattiau, P., 2008. Brucella suis identification and biovar typing by realtime PCR. Veterinary Microbiology 131, 376-385.

Garcia-Yoldi, D., Le Fleche, P., De Miguel, M.J., Munoz, P.M., Blasco, J.M., Cvetnic, Z., Marin, C.M., Vergnaud, G., Lopez-Goni, I., 2007. Comparison of multiple-locus variable-number tandem-repeat analysis with other PCR-based methods for typing Brucella suis isolates. Journal of Clinical Microbiology 45, 4070-4072.

Ghanem, Y.M., El-Khodery, S.A., Saad, A.A., Abdelkader, A.H., Heybe, A., Musse, Y.A., 2009. Seroprevalence of camel brucellosis (Camelus dromedarius) in Somaliland. Tropical Animal Health and Production $41,1779-1786$.

Glynn, M.K., Lynn, T.V., 2008. Brucellosis. Journal of the American Veterinary Medical Association 233, 900-908.

Godfroid, J., Cloeckaert, A., Liautard, J.P., Kohler, S., Fretin, D., Walravens, K., Garin-Bastuji, B., Letesson, J.J., 2005. From the discovery of the Malta fever's agent to the discovery of a marine mammal reservoir, brucellosis has continuously been a re-emerging zoonosis. Veterinary Research 36, 313-326.

Godfroid, J., Michel, P., Uytterhaegen, L., Desmedt, C., Rasseneur, F., Boelaert, F., Saegerman, C., Patigny, X., 1994. Brucella-Suis biotype 2 infection of wild boars (Sus scrofa) in Belgium. Annales de Medecine Veterinaire 138, 263-268.

Godfroid, J., Nielsen, K., Saegerman, C., 2010. Diagnosis of brucellosis in livestock and wildlife. Croatian Medical Journal 51, 296-305.

Gopaul, K.K., Koylass, M.S., Smith, C.J., Whatmore, A.M., 2008. Rapid identification of Brucella isolates to the species level by real time PCR based single nucleotide polymorphism (SNP) analysis. BMC Microbiology, 8.

Gopaul, K.K., Sells, J., Bricker, B.J., Crasta, O.R., Whatmore, A.M., 2010. Rapid and reliable single nucleotide polymorphism-based differentiation of Brucella live vaccine strains from field strains. Journal of Clinical Microbiology 48, 1461-1464.

Gorvel, J.P., 2008. Brucella: a Mr "Hide" converted into Dr Jekyll. Microbes and Infection 10, 1010-1013.

Gorvel, J.P., Moreno, E., 2002. Brucella intracellular life: from invasion to intracellular replication. Veterinary Microbiology 90, 281-297.

Gyles, C., 2010. Agroterrorism. Revue Veterinaire Canadienne 51, 347-348.

Hadorn, D.C., Stark, K.D.C., 2008. Evaluation and optimization of surveillance systems for rare and emerging infectious diseases. Veterinary Research, 39.

Haileselassie, M., Shewit, K., Moses, K., 2010. Serological survey of bovine brucellosis in barka and arado breeds (Bos indicus) of Western Tigray, Ethiopia. Preventive Veterinary Medicine 94, 28-35.

Halling, S.M., Tatum, F.M., Bricker, B.J., 1993. Sequence and characterization of an insertion-sequence, IS711, from Brucella-Ovis. Gene 133, 123-127.

Hendricks, M.K., Perez, E.M., Burger, P.J., Mouton, P.A., 1995. Brucellosis in childhood in the Western Cape. South African Medical Journal 85, $176-178$.

Herman, L., Deridder, H., 1992. Identification of Brucella spp. by using the polymerase chain-reaction. Applied and Environmental Microbiology 58, 2099-2101.

Herrera, E., Palomares, G., az-Aparicio, E., 2008. Milk production increase in a dairy farm under a six-year brucellosis control program. Animal Biodiversity and Emerging Diseases: Prediction and Prevention 1149, 296-299.

Herrera-Lopez, E., Suarez-Guemes, F., Hernandez-Andrade, L., CordovaLopez, D., Diaz-Aparicio, E., 2010. Epidemiological study of brucellosis in cattle, immunized with Brucella abortus RB51 vaccine in endemic zones. Vaccine 28, F59-F63.

Hoover, D.L., Friedlander, A., 2010. Brucellosis. In: Zajtchuk, R. (Ed.), Textbook of Military Medicine: Medical Aspects of Chemical and Biological 
Warfare. US Department of the Army, Surgeon General, and the Borden Institute, Washington, DC, pp. 513-521.

Irwin, M.J., Massey, P.D., Walker, B., Durrheim, D.N., 2010. Feral pig hunting: a risk factor for human brucellosis in north-west NSW? New South Wales Public Health Bulletin 20, 192-194.

Jennings, G.J., Hajjeh, R.A., Girgis, F.Y., Fadeel, M.A., Maksoud, M.A., Wasfy, M.O., El Sayed, N., Srikantiah, P., Luby, S.P., Earhart, K., Mahoney, F.J., 2007. Brucellosis as a cause of acute febrile illness in Egypt. Transactions of the Royal Society of Tropical Medicine and Hygiene 101, 707-713.

Jergefa, T., Kelay, B., Bekana, M., Teshale, S., Gustafson, H., Kindahl, H., 2009. Epidemiological study of bovine brucellosis in three agro-ecological areas of central Oromiya, Ethiopia. Revue Scientifique et TechniqueOffice International des Epizooties 28, 933-943.

John, K., Kazwala, R., Mfinanga, G.S., 2008. Knowledge of causes, clinical features and diagnosis of common zoonoses among medical practitioners in Tanzania. BMC Infectious Diseases, 8.

Jones, R.D., Kelly, L., England, T., MacMillan, A., Wooldridge, M., 2004 A quantitative risk assessment for the importation of brucellosisinfected breeding cattle into Great Britain from selected European countries. Preventive Veterinary Medicine 63, 51-61.

Kattar, M.M., Jaafar, R.F., Araj, G.F., Le Fleche, P., Matar, G.M., Rached, R.A., Khalife, S., Vergnaud, G., 2008. Evaluation of a multilocus variablenumber tandem-repeat analysis scheme for typing human Brucella isolates in a region of brucellosis endemicity. Journal of Clinical Microbiology 46, 3935-3940.

Kohler, S., Foulongne, V., Ouahrani-Bettache, S., Bourg, G., Teyssier, J., Ramuz, M., Liautard, J.P., 2002. The analysis of the intramacrophagic virulome of Brucella suis deciphers the environment encountered by the pathogen inside the macrophage host cell. Proceedings of the National Academy of Sciences of the United States of America 99, 15711-15716.

Koylass, M.S., King, A.C., Edwards-Smallbone, J., Gopaul, K.K., Perrett, L.L., Whatmore, A.M., 2010. Comparative performance of SNP typing and 'Bruce-ladder' in the discrimination of Brucella suis and Brucella canis. Veterinary Microbiology 142, 450-454.

Lamontagne, J., Beland, M., Forest, A., Cote-Martin, A., Nassif, N., Tomaki, F., Moriyon, I., Moreno, E., Paramithiotis, E., 2010. Proteomics-based confirmation of protein expression and correction of annotation errors in the Brucella abortus genome. BMC Genomics, 11.

Le Fleche, P., Jacques, I., Grayon, M., Al Dahouk, S., Bouchon, P., Denoeud, F., Nockler, K., Neubauer, H., Guilloteau, L.A., Vergnaud, G., 2006. Evaluation and selection of tandem repeat loci for a Brucella MLVA typing assay. BMC Microbiology, 6.

Leal-Klevezas, D.S., Martinez-Vazquez, I.O., Lopez-Merino, A., MartinezSoriano, J.P., 1995. Single-step PCR for detection of Brucella spp. from blood and milk of infected animals. Journal of Clinical Microbiology 33, 3087-3090.

Letesson, J.J., Lestrate, P., Delrue, R.M., Danese, I., Bellefontaine, F., Fretin, D., Taminiau, B., Tibor, A., Dricot, A., Deschamps, C., Haine, V., Leonard, S., Laurent, T., Mertens, P., Vandenhaute, J., De Bolle, X., 2002. Fun stories about Brucella: the "furtive nasty bug". Veterinary Microbiology 90, 317-328.

Lopez-Goni, I., Garcia-Yoldi, D., Marin, C.M., De Miguel, M.J., Munoz, P.M., Blasco, J.M., Jacques, I., Grayon, M., Cloeckaert, A., Ferreira, A.C., Cardoso, R., De Sa, M.I.C., Walravens, K., Albert, D., Garin-Bastuji, B., 2008. Evaluation of a multiplex PCR assay (Bruce-ladder) for molecular typing of all Brucella species, including the vaccine strains. Journal of Clinical Microbiology 46, 3484-3487.

Lucero, N.E., Ayala, S.M., Escobar, G.I., Jacob, N.R., 2008. Brucella isolated in humans and animals in Latin America from 1968 to 2006. Epidemiology and Infection 136, 496-503.

Lucero, N.E., Corazza, R., Almuzara, M.N., Reynes, E., Escobar, G.I., Boeri, E., Ayala, S.M., 2010. Human Brucella canis outbreak linked to infection in dogs. Epidemiology and Infection 138, 280-285.

Luna-Martinez, J.E., Mejia-Teran, C., 2002. Brucellosis in Mexico: current status and trends. Veterinary Microbiology 90, 19-30.

Makita, K., Fevre, E.M., Waiswa, C., Kaboyo, W., Bronsvoort, B.M.D.C., Eisler, M.C., Welburn, S.C., 2008. Human brucellosis in urban and peri-urban areas of Kampala, Uganda. Animal Biodiversity and Emerging Diseases: Prediction and Prevention 1149, 309-311.

Maquart, M., Fardini, Y., Zygmunt, M.S., Cloeckaert, A., 2008. Identification of novel DNA fragments and partial sequence of a genomic island specific of Brucella pinnipedialis. Veterinary Microbiology 132, 181-189.

Marcotty, T., Matthys, F., Godfroid, J., Rigouts, L., Ameni, G., van Pittius, N.G., Kazwala, R., Muma, J., van Helden, P., Walravens, K., de Klerk, L.M., Geoghegan, C., Mbotha, D., Otte, M., Amenu, K., bu Samra, N., Botha, C., Ekron, M., Jenkins, A., Jori, F., Kriek, N., McCrindle, C., Michel,
A., Morar, D., Roger, F., Thys, E., van den Bossche, P., 2009. Zoonotic tuberculosis and brucellosis in Africa: neglected zoonoses or minor public-health issues? The outcomes of a multi-disciplinary workshop. Annals of Tropical Medicine and Parasitology 103, 401-411.

Marianelli, C., Petrucca, A., Pasquali, P., Ciuchini, F., Papadopoulou, S., Cipriani, P., 2008. Use of MLVA-16 typing to trace the source of a laboratory-acquired Brucella infection. Journal of Hospital Infection 68, 274-276.

Martin, R.A.J., Cameron, A.R., Greiner, M., 2007. Demonstrating freedom from disease using multiple complex data sources 1: a new methodology based on scenario trees. Preventive Veterinary Medicine 79, 71-97.

Martins, H., Garin-Bastuji, B., Lima, F., Flor, L., Fonseca, A.P., Boinas, F., 2010. Reply to Letter to the Editor by Blasco and Moriyon (2009) concerning the manuscript "Eradication of bovine brucellosis (BB) in the Azores, Portugal-outcome of a 5-year programme (2002-2007) based on test-and-slaughter and RB51 vaccination" by H. Martins et al. (2009). Preventive Veterinary Medicine 94, 158-162.

Martins, H., Garin-Bastuji, B., Lima, F., Flor, L., Pina Fonseca, A., Boinas, F., 2009. Eradication of bovine brucellosis in the Azores, Portugal-outcome of a 5-year programme (2002-2007) based on test-and-slaughter and RB51 vaccination. Preventive Veterinary Medicine 90, 80-89.

Matope, G., Bhebhe, E., Muma, J.B., Lund, A., Skjerve, E., 2010. Herd-level factors for Brucella seropositivity in cattle reared in smallholder dairy farms of Zimbabwe. Preventive Veterinary Medicine 94, 213-221.

Mayer-Scholl, A., Draeger, A., Gollner, C., Scholz, H.C., Nockler, K., 2010. Advancement of a multiplex PCR for the differentiation of all currently described Brucella species. Journal of Microbiological Methods $80,112-114$

McDermott, J.J., Arimi, S.M., 2002. Brucellosis in sub-Saharan Africa: epidemiology, control and impact. Veterinary Microbiology 90, 111-134.

McDonald, W.L., Jamaludin, R., Mackereth, G., Hansen, M., Humphrey, S., Short, P., Taylor, T., Swingler, J., Dawson, C.E., Whatmore, A.M., Stubberfield, E., Perrett, L.L., Simmons, G., 2006. Characterization of a Brucella sp. strain as a marine-mammal type despite isolation from a patient with spinal osteomyelitis in New Zealand. Journal of Clinical Microbiology 44, 4363-4370.

Moreno, E., 2002. Brucellosis in Central America. Veterinary Microbiology 90, 31-38.

Moreno, E., Cloeckaert, A., Moriyon, I., 2002. Brucella evolution and taxonomy. Veterinary Microbiology 90, 209-227.

Moriyon, I., Grillo, M.J., Monreal, D., Gonzalez, D., Marin, C., Lopez-Goni, I., Mainar-Jaime, R.C., Moreno, E., Blasco, J.M., 2004. Rough vaccines in animal brucellosis: structural and genetic basis and present status. Veterinary Research 35, 1-38.

Muma, J.B., Godfroid, J., Samui, K.L., Skjerve, E., 2007a. The role of Brucella infection in abortions among traditional cattle reared in proximity to wildlife on the Kafue flats of Zambia. Revue Scientifique et TechniqueOffice International des Epizooties 26, 721-730.

Muma, J.B., Lund, A., Nielsen, K., Matope, G., Munyeme, M., Mwacalimba, K., Skjerve, E., 2009. Effectiveness of Rose Bengal test and fluorescence polarization assay in the diagnosis of Brucella spp. infections in free range cattle reared in endemic areas in Zambia. Tropical Animal Health and Production 41, 723-729.

Muma, J.B., Samui, K.L., Oloya, J., Munyeme, M., Skjerve, E., 2007b. Risk factors for brucellosis in indigenous cattle reared in livestockwildlife interface areas of Zambia. Preventive Veterinary Medicine 80 , 306-317.

Muma, J.B., Samui, K.L., Siamudaala, V.M., Oloya, J., Matope, G., Omer, M.K., Munyeme, M., Mubita, C., Skjerve, E., 2006. Prevalence of antibodies to Brucella spp. And individual risk factors of infection in traditional cattle, goats and sheep reared in livestock-wildlife interface areas of Zambia. Tropical Animal Health and Production 38, 195-206.

Musa, M.T., Eisa, M.Z.M., El Sanousi, E.M., Wahab, M.B.A., Perrett, L., 2008. Brucellosis in camels (Camelus dromedarius) in Darfur, Western Sudan. Journal of Comparative Pathology 138, 151-155.

Musa, M.T., Jahans, K.L., 1990. The isolation of Brucella-Melitensis biovar3 from a testicular hygroma of a ram in a nomadic flock of sheep and goats in Western Sudan. Journal of Comparative Pathology 103, 467-470.

Neta, A.V.C., Mol, J.P.S., Xavier, M.N., Paixтo, T.A., Lage, A.P., Santos, R.L., 2010. Pathogenesis of bovine brucellosis. The Veterinary Journal 184 , 146-155.

Nicoletti, P., 1990. Vaccination. In: Nielsen, K.H., Duncan, J.R. (Eds.), Animal Brucellosis. CRC Press, Boca Raton, pp. 283-299.

Nockler, K., Maves, R., Cepeda, D., Draeger, A., Mayer-Scholl, A., Chacaltana, J., Castaneda, M., Espinosa, B., Castillo, R., Hall, E., Al Dahouk, S., Gilman, R.H., Cabeza, F., Smits, H.L., 2009. Molecular epidemiology of Brucella 
genotypes in patients at a major hospital in Central Peru. Journal of Clinical Microbiology 47, 3147-3155.

Nomura, A., Imaoka, K., Imanishi, H., Shimizu, H., Nagura, F., Maeda, K., Tomino, T., Fujita, Y., Kimura, M., Stein, G.H., 2010. Human Brucella canis infections diagnosed by blood culture. Emerging Infectious Diseases 16, 1183-1185.

O'Callaghan, D., Cazevieille, C., lardet-Servent, A., Boschiroli, M.L., Bourg, G., Foulongne, V., Frutos, P., Kulakov, Y., Ramuz, M., 1999. A homologue of the Agrobacterium tumefaciens VirB and Bordetella pertussis Ptl type IV secretion systems is essential for intracellular survival of Brucella suis. Molecular Microbiology 33, 1210-1220.

Ocholi, R.A., Kwaga, J.K.P., Ajogi, I., Bale, J.O.O., 2004. Phenotypic characterization of Brucella strains isolated from livestock in Nigeria. Veterinary Microbiology 103, 47-53.

Olsen, S., Tatum, F., 2010. Bovine brucellosis. Veterinary Clinics of North America-Food Animal Practice 26, 15-27.

Olsen, S.C., Hennager, S.G., 2010. Immune responses and protection against experimental Brucella suis biovar 1 challenge in nonvaccinated or B. abortus strain RB51-vaccinated cattle. Clinical and Vaccine Immunology 17, 1891-1895.

Omer, M.K., Skjerve, E., Woldehiwet, Z., Holstad, G., 2000. Risk factors for Brucella spp. infection in dairy cattle farms in Asmara, State of Eritrea. Preventive Veterinary Medicine 46, 257-265.

Osterman, B., Moriyon, I., 2006. International Committee on Systematics of Prokaryotes, Subcommittee on the taxonomy of Brucella: minutes of the meeting, 17 September 2003, Pamplona, Spain. International Journal of Systematic and Evolutionary Microbiology 56, 1173-1175.

Ouahrani, S., Michaux, S., Widada, J.S., Bourg, G., Tournebize, R., Ramuz, M., Liautard, J.P., 1993. Identification and sequence-analysis of IS6501, an insertion-sequence in Brucella spp.: relationship between genomic structure and the number of IS6501 copies. Journal of General Microbiology $139,3265-3273$.

Pappas, G., Panagopoulou, P., Christou, L., Akritidis, N., 2006a. Brucella as a biological weapon. Cellular and Molecular Life Sciences 63, 2229-2236.

Pappas, G., Papadimitriou, P., Akritidis, N., Christou, L., Tsianos, E.V., 2006b. The new global map of human brucellosis. Lancet Infectious Diseases 6, 91-99.

Pappas, G., Akritidis, N., Bosilkovski, M., Tsianos, E., 2005. Brucellosis. New England Journal of Medicine 352, 2325-2336.

Paul, J., Gilks, C., Batchelor, B., Ojoo, J., Amir, M., Selkon, J.B., 1995. Serological responses to brucellosis in HIV-seropositive patients. Transactions of the Royal Society of Tropical Medicine and Hygiene 89, 228-230.

Poester, F.P., Goncalves, V.S.P., Lage, A.P., 2002. Brucellosis in Brazil. Veterinary Microbiology 90, 55-62.

Refai, M., 2002. Incidence and control of brucellosis in the Near East region. Veterinary Microbiology 90, 81-110.

Renukaradhya, G.J., Isloor, S., Rajasekhar, M., 2002. Epidemiology, zoonotic aspects, vaccination and control/eradication of brucellosis in India. Veterinary Microbiology 90, 183-195.

Rijpens, N.P., Jannes, G., VanAsbroeck, M., Rossau, R., Herman, L.M.F., 1996. Direct detection of Brucella spp. in raw milk by PCR and reverse hybridization with 16S-23S rRNA spacer probes. Applied and Environmental Microbiology 62, 1683-1688.

Rittig, M.G., Kaufmann, A., Robins, A., Shaw, B., Sprenger, H., Gemsa, D., Foulongne, V., Rouot, B., Dornand, J., 2003. Smooth and rough lipopolysaccharide phenotypes of Brucella induce different intracellular trafficking and cytokine/chemokine release in human monocytes. Journal of Leukocyte Biology 74, 1045-1055.

Roop, R.M., Gaines, J.M., Anderson, E.S., Caswell, C.C., Martin, D.W., 2009. Survival of the fittest: how Brucella strains adapt to their intracellular niche in the host. Medical Microbiology and Immunology 198, 221-238.

Rotz, L.D., Khan, A.S., Lillibridge, S.R., Ostroff, S.M., Hughes, J.M., 2002. Public health assessment of potential biological terrorism agents. Emerging Infectious Diseases 8, 225-230.

Saegerman, C., 2006. Epidemiosurveillance of rare events in Belgian cattle. Annales de Medecine Veterinaire 150, 4-9.

Saegerman, C., Berkvens, D., Godfroid, J., Walravens, K., 2010. Infectious and Parasitic Disease of Livestock. Lavoisier and Commonwealth Agricultural Bureau-International, pp. 971-1001.

Samaha, H., Al-Rowaily, M., Khoudair, R.M., Ashour, H.M., 2008. Multicenter study of brucellosis in Egypt. Emerging Infectious Diseases 14, 1916-1918.

Samartino, L.E., 2002. Brucellosis in Argentina. Veterinary Microbiology $90,71-80$.

Schelling, E., Diguimbaye, C., Daoud, S., Nicolet, J., Boerlin, P., Tanner, M., Zinsstag, J., 2003. Brucellosis and Q-fever seroprevalences of nomadic pastoralists and their livestock in Chad. Preventive Veterinary Medicine 61, 279-293.

Schlabritz-Loutsevitch, N.E., Whatmore, A.M., Quance, C.R., Koylass, M.S., Cummins, L.B., Dick, E.J., Snider, C.L., Cappelli, D., Ebersole, J.L., Nathanielsz, P.W., Hubbard, G.B., 2009. A novel Brucella isolate in association with two cases of stillbirth in non-human primates-first report. Journal of Medical Primatology 38, 70-73.

Scholz, H.C., Al Dahouk, S., Tomaso, H., Neubauer, H., Witte, A., Schloter, M., Kampfer, P., Falsen, E., Pfeffer, M., Engel, M., 2008a. Genetic diversity and phylogenetic relationships of bacteria belonging to the Ochrobactrum-Brucella group by recA and 16S rRNA gene-based comparative sequence analysis. Systematic and Applied Microbiology 31, $1-16$.

Scholz, H.C., Hubalek, Z., Sedlacek, I., Vergnaud, G., Tomaso, H., Al Dahouk, S., Melzer, F., Kampfer, P., Neubauer, H., Cloeckaert, A., Maquart, M., Zygmunt, M.S., Whatmore, A.M., Falsen, E., Bahn, P., Gollner, C., Pfeffer, M., Huber, B., Busse, H.J., Nockler, K., 2008b. Brucella microti sp. nov., isolated from the common vole Microtus arvalis. International Journal of Systematic and Evolutionary Microbiology 58, 375-382.

Scholz, H.C., Nockler, K., Gollner, C., Bahn, P., Vergnaud, G., Tomaso, H., Al Dahouk, S., Kampfer, P., Cloeckaert, A., Maquart, M., Zygmunt, M.S., Whatmore, A.M., Pfeffer, M., Huber, B., Busse, H.J., De, B.K., 2010. Brucella inopinata sp nov., isolated from a breast implant infection. International Journal of Systematic and Evolutionary Microbiology 60, 801-808.

Shen, M.W., 2008. Diagnostic and therapeutic challenges of childhood brucellosis in a nonendemic country. Pediatrics 121, E1178-E1183.

Sohn, A.H., Probert, W.S., Glaser, C.A., Gupta, N., Bollen, A.W., Wong, J.D., Grace, E.M., McDonald, W.C., 2003. Human neurobrucellosis with intracerebral granuloma caused by a marine mammal Brucella spp. Emerging Infectious Diseases 9, 485-488.

Stoffregen, W.C., Olsen, S.C., Bricker, B.J., 2006. Parenteral vaccination of domestic pigs with Brucella abortus strain RB51. American Journal of Veterinary Research 67, 1802-1808.

Stoffregen, W.C., Olsen, S.C., Wheeler, C.J., Bricker, B.J., Palmer, M.V., Jensen, A.E., Halling, S.M., Alt, D.P., 2007. Diagnostic characterization of a feral swine herd enzootically infected with Brucella. Journal of Veterinary Diagnostic Investigation 19, 227-237.

Swai, E.S., Schoonman, L., 2009. Human brucellosis: seroprevalence and risk factors related to high risk occupational groups in Tanga Municipality, Tanzania. Zoonoses and Public Health 56, 183-187.

Tiller, R.V., Gee, J.E., Frace, M.A., Taylor, T.K., Setubal, J.C., Hoffmaster, A.R., De, B.K., 2010. Characterization of novel Brucella strains originating from wild native rodent species in North Queensland, Australia. Applied and Environmental Microbiology 76, 5837-5845.

Ugalde, R.A., 1999. Intracellular lifestyle of Brucella spp. common genes with other animal pathogens, plant pathogens, and endosymbionts. Microbes and Infection 1, 1211-1219.

Valdezate, S., Cervera, I., Hernandez, P., Navarro, A., Nieto, J.A.S., 2007. Characterisation of human outbreaks of brucellosis and sporadic cases by the use of hyper-variable octameric oligonucleotide fingerprint (HOOF) variable number tandem repeats. Clinical Microbiology and Infection $13,887-892$.

Valdezate, S., Navarro, A., Villalon, P., Carrasco, G., Saez-Nieto, J.A., 2010. Epidemiological and phylogenetic analysis of Spanish human Brucella melitensis strains by multiple-locus variable-number tandem-repeat typing, hypervariable octameric oligonucleotide fingerprinting, and rpoB typing. Journal of Clinical Microbiology 48, 2734-2740.

Van Campen, H., Rhyan, J., 2010. The role of wildlife in diseases of cattle. Veterinary Clinics of North America-Food Animal Practice 26, 147-161.

Vargas, F.J., 2002. Brucellosis in Venezuela. Veterinary Microbiology 90, 39-44.

Velasco, J., Romero, C., Lopez-Goni, I., Leiva, J., Diaz, R., Moriyon, I., 1998. Evaluation of the relatedness of Brucella spp. and Ochrobactrum anthropi and description of Ochrobactrum intermedium sp. nov., a new species with a closer relationship to Brucella spp. International Journal of Systematic Bacteriology 48, 759-768.

Verger, J.M., Garinbastuji, B., Grayon, M., Mahe, A.M., 1989. BrucellaMelitensis infection in cattle in France. Annales de Recherches Veterinaires 20, 93-102.

Verger, J.M., Grimont, F., Grimont, P.A.D., Grayon, M., 1985. Brucella, a monospecific genus as shown by deoxyribonucleic-acid hybridization. International Journal of Systematic Bacteriology 35, 292-295.

Viadas, C., Rodriguez, M.C., Sangari, F.J., Gorvel, J.P., Garcia-Lobo, J.M., Lopez-Goni, I., 2010. Transcriptome analysis of the Brucella abortus BvrR/BvrS two-component regulatory system. Plos One, 5. 
Villarroel, M., Grell, M., Saenz, R., 2000. Isolation and identification of Brucella abortus RB 51 in human: first report in Chile. Archivos de Medicina Veterinaria 32, 89-91.

Vizcaino, N., Cloeckaert, A., Verger, J.M., Grayon, M., Fernandez-Lago, L., 2000. DNA polymorphism in the genus Brucella. Microbes and Infection 2, 1089-1100.

Weeks, J.N., Galindo, C.L., Drake, K.L., Adams, G.L., Garner, H.R., Ficht, T.A., 2010. Brucella melitensis VjbR and C-12-HSL regulons: contributions of the N-dodecanoyl homoserine lactone signaling molecule and LuxR homologue VjbR to gene expression. BMC Microbiology, 10.

Whatmore, A.M., 2009. Current understanding of the genetic diversity of Brucella, an expanding genus of zoonotic pathogens. Infection Genetics and Evolution 9, 1168-1184.

Whatmore, A.M., Perrett, L.L., MacMillan, A.P., 2007. Characterisation of the genetic diversity of Brucella by multilocus sequencing. BMC Microbiology, 7.
Whatmore, A.M., Shankster, S.J., Perrett, L.L., Murphy, T.J., Brew, S.D., Thirlwall, R.E., Cutler, S.J., MacMillan, A.P., 2006. Identification and characterization of variable-number tandem-repeat markers for typing of Brucella spp. Journal of Clinical Microbiology 44, 1982-1993.

Willyard, C., 2007. Lack of training in biodefense research leading to dangerous leaks. Nature Medicine 13, 1004.

Yazdi, H.S., Kafi, M., Haghkhah, M., Tamadon, A., Behroozikhah, A.M., Ghane, M., 2009. Abortions in pregnant dairy cows after vaccination with Brucella abortus strain RB51. Veterinary Record 165, 570-571.

Zinsstag, J., Schelling, E., Roth, F., Bonfoh, B., de Savigny, D., Tanner, M., 2007. Human benefits of animal interventions for zoonosis control. Emerging Infectious Diseases 13, 527-531.

Zygmunt, M.S., Maquart, M., Bernardet, N., Doublet, B., Cloeckaert, A., 2010. Novel IS711-specific chromosomal locations useful for identification and classification of marine mammal Brucella strains. Journal of Clinical Microbiology 48, 3765-3769. 